BMJ

Open

Gastroenterology

\title{
Who uses probiotics and why? A survey study conducted among general gastroenterology patients
}

\author{
Elissa Lynch, Jordan Troob, Benjamin Lebwohl, Daniel E Freedberg
}

To cite: Lynch E, Troob J, Lebwohl B, et al. Who uses probiotics and why? A survey study conducted among general gastroenterology patients. BMJ Open Gastro 2021;8:e000742. doi:10.1136/ bmjgast-2021-000742

- Additional supplemental material is published online only. To view, please visit the journal online (http://dx.doi. org/10.1136/bmjgast-2021000742).

Received 12 July 2021 Accepted 17 August 2021
A) Check for updates

(C) Author(s) (or their employer(s)) 2021. Re-use permitted under CC BY-NC. No commercial re-use. See rights and permissions. Published by BMJ.

Division of Digestive and Liver Diseases, Columbia University, New York, NY, USA

Correspondence to Dr Daniel E Freedberg; def2004@cumc.columbia.edu

\begin{abstract}
Background The rapid growth of the probiotic industry suggests patients will continue to seek advice from gastroenterologists about probiotics. To best address patient questions and concerns, we must first understand who uses probiotics and why.

Methods This was a cross-sectional study conducted in the endoscopy suite of an academic hospital from June to October of 2019. Surveys were anonymous and contained a combination of multiple choice, free text and Likert scale questions. Participants privately completed a paper survey in English or Spanish and the results were reviewed with them by study personnel to clarify responses. Descriptive statistics were generated and multivariable logistic regression modelling was used to compare characteristics of probiotic users versus non-users.
\end{abstract}

Results During the 5-month study period, 600 patients were approached and 537 (90\%) agreed to participate. Among participants, $89 \%$ completed at least 24 survey items and were included in the analysis. Overall, $27 \%$ of patients reported probiotic use. Bloating, rather than diarrhoea, was the main gastrointestinal symptom associated with use of probiotics (aOR $2.59,95 \% \mathrm{Cl} 1.52$ to 4.44 for bloating; aOR $1.03,95 \% \mathrm{Cl} 0.55$ to 1.94 for diarrhoea). Frequent reasons cited for taking probiotics were the beliefs that they improved overall health and longevity (54\%) and that they improved gastrointestinal symptoms (45\%).

Conclusions Probiotic use is common among general gastroenterology patients, many of whom believe that probiotics confer general rather than specific gastrointestinal health benefits. Symptoms - especially bloating — and not sociodemographic factors seem to motivate probiotic use. By understanding patient expectations for probiotics, clinicians can better advise them.

\section{INTRODUCTION}

Probiotics have been defined by the Food and Agriculture Organization of the United Nations (FAO)/WHO as "live microorganisms which, when administered in adequate amounts, confer a health benefit on the host'. ${ }^{1}$ Reviewing the evidence for health benefits related to probiotics (including treatment of diarrhoea and constipation), the FAO/WHO stressed the need for more studies. Guidelines from the British Society
Summary box

What is already known about this subject?

- Use of probiotics seems to be common among general gastroenterology patients, yet it is uncertain which kinds of patients use probiotics and why.

What are the new findings?

- About one third of general gastroenterology patients used probiotics at least occasionally; bloating rather than diarrhoea was the main gastrointestinal symptom associated with use of probiotics. Probiotics users were more likely to believe that probiotics conferred general health benefits rather than specific gastrointestinal benefits.

How might it impact on clinical practice in the foreseeable future?

- Clinicians must be aware of the reasons driving probiotic use if they are to effectively advise their patients about probiotics.

of Gastroenterology support the use of probiotics for abdominal pain in irritable bowel syndrome (a weak recommendation based on low-quality evidence) $)^{2}$ whereas guidelines from the American Gastroenterological Association (AGA) recommend probiotics only for preterm infants, for children with acute infectious gastroenteritis, or for children or adults with pouchitis. ${ }^{3}$ Despite the lack of highquality evidence supporting use of probiotics, they have become a US $\$ 43$ billion industry in the USA, projected to grow to US $\$ 75$ billion by $2025 .{ }^{4}$ This study was performed to identify the reasons why general gastroenterology patients use probiotics, a question that has received little prior attention.

Probiotics are often advertised as a healthy and safe supplement to treat gastrointestinal symptoms, yet great uncertainty remains regarding their optimal use. ${ }^{3}$ A National Health Statistics Report on complementary health approaches reported an increase in the prevalence of probiotics use: from $0.3 \%$ in 2007 to $1.6 \%$ in $2012 .^{5}$ After vitamins and 
minerals, probiotics and/or prebiotics are the third most popular dietary supplement among adults. ${ }^{6}$ Probiotic use appears to be much more common among gastrointestinal patients; of those who use complementary and alternative therapies (CAMs), $45 \%$ also report using probiotics. $^{7}$

Use of probiotics appears to be common, yet relatively little is known about who uses probiotics and why, with prior studies focused mostly on CAMs and/or use of probiotics in the general medical population rather than in those seeking specialty consultation. Patients frequently seek advice from gastroenterologists regarding probiotics but no previous study has described probiotic use among the general gastroenterology population. To better understand the prevalence of probiotic use and the reasons underlying use, we conducted a cross-sectional survey study among general gastroenterology patients.

\section{METHODS}

\section{Population and study design}

This was a cross-sectional study conducted in the endoscopy suite of Columbia University Irving Medical Center (CUIMC) from June to October of 2019. CUIMC serves a patient population that is diverse both in racial/ethnic composition and economically. The endoscopy suite was chosen for the study location because we expected that patients would be likely to agree to participate in a survey while awaiting endoscopy, and that we would have a high survey participation rate and therefore results that could reasonably be extrapolated to a general gastroenterology population (ie, minimal respondent bias). Using convenience sampling, outpatients coming for endoscopic procedures were asked to complete the survey, unless they had previously completed it during the study period.

\section{Survey instrument}

The survey instrument had 57 questions including free response, multiple choice and Likert scale questions. During survey development, face validation was performed with five patients with rephrasing of questions to enhance comprehension based on their feedback. If survey respondents asked for guidance regarding the definition used for probiotics, the FAO/WHO operationalisation of probiotics was given. Final survey questions were spread across four domains (complete survey reproduced in online supplemental data 1). The first survey domain was a food frequency questionnaire derived from the National Health Interview Survey and validated for assessment of fat and fibre intake ${ }^{89}$; the second domain was related to whether and why probiotics were taken; the third domain included demographics and subjective health information; and the fourth domain asked for views about probiotics. The survey was anonymous, and contained no personally identifiable health data. To preserve privacy, zip code of residence was used to extrapolate household income based on 2017 US Census Bureau statistics. ${ }^{10}$

\section{Enrolment and survey administration}

Study enrolment began on 10 June 2019 and ended on 10 October 2019. Patients awaiting endoscopy were approached in person regarding the survey in the endoscopy suite IV area. Patients who agreed to participate were handed a printed survey in English or Spanish and completed the questions alone; study personnel collected the completed surveys and then reviewed them with participants, clarifying responses to avoid missing data. Surveys were considered complete if a minimum of 24 survey questions contained valid responses, including the question pertaining to probiotic use.

\section{Analysis}

At the end of the study enrolment period, survey data were tabulated and visualised as histograms, violin plots and bar charts. Descriptive statistics were generated and $\chi^{2}$ or rank-sum tests (for continuous data) were used to compare characteristics of probiotic users to non-users. For this analysis, probiotic use was classified categorically based on the answer to the question 'How regularly do you take probiotics?' Those who took probiotics occasionally or more often were classified as probiotic users and those who took probiotics 'never' were classified as non-users. Multivariable logistic regression modelling was used to assess the independent association between specific symptoms (eg, diarrhoea) and use of probiotics, after adjusting for other symptoms. For all analyses, alpha 0.05 was considered statistically significant.

\section{RESULTS}

\section{Population}

A total of 600 patients were approached and 537 (90\%) agreed to participate. Among participants, 479/537 (89\%) completed at least 24 survey items and were included in the analysis. The analysed surveys were $96.7 \%$ complete overall. Raw data from the surveys are available in online supplemental data 2.

\section{Demographics}

Median study age was 60 (IQR 55 to 65 ) and $53.8 \%$ of participants were women. The racial composition of the study population was similar to that of the US population with $63 \%$ white, $21 \%$ Hispanic and $8 \%$ black. ${ }^{11}$ Twenty-six per cent of respondents self-identified as Hispanic and $5 \%$ spoke Spanish only.

\section{Probiotic use}

One hundred thirty patients $(27 \%)$ reported probiotic use, with the majority of use sporadic as opposed to daily (figure 1). Asked which probiotics they took, most participants were unsure (78\%, figure 2). Prescription probiotics were more likely to be identified by name than over-the-counter probiotics. Among probiotic users, a median of US $\$ 20 /$ month (IQR US $\$ 0$ to US\$40) was spent on probiotics. The most common reasons listed for using probiotics were the beliefs that they improve overall health and longevity $(54 \%)$ and that they improve 


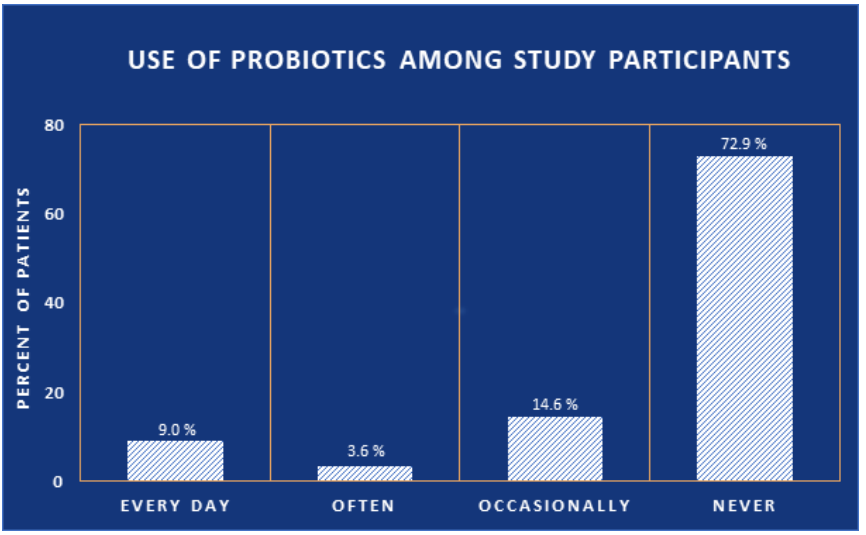

Figure 1 Use of probiotics among patients in the study.

gastrointestinal symptoms (45\%). Less often cited were the beliefs that probiotics help maintain healthy weight $(9 \%)$ or improve non-gastrointestinal symptoms (8\%) (figure 3). When stratified by the reason for the endoscopic procedure, rates of probiotic use were similar among those having screening versus diagnostic procedures $\left(25 \%\right.$ and $30 \%$ respectively, $\chi^{2} p=0.24$.

\section{Comparing probiotic users to non-users}

We compared characteristics of probiotic users versus non-users. There were no sociodemographic differences based on use of probiotics including no differences in age, race/ethnicity, preferred questionnaire language or income (table 1). The study instrument included a food frequency questionnaire validated for fat and fibre intake; there were no detectable differences between probiotics users and non-users in dietary intake, use of vitamins, artificial sweeteners or alcohol (online supplemental table 1).

\section{Symptoms, comparing probiotic users to non-users}

Next, we evaluated symptomatology. There were no differences in self-reported overall health, happiness, activity levels or quality of diet based on use of probiotics. Compared with non-users, probiotic users were more likely to have any gastrointestinal symptoms, to

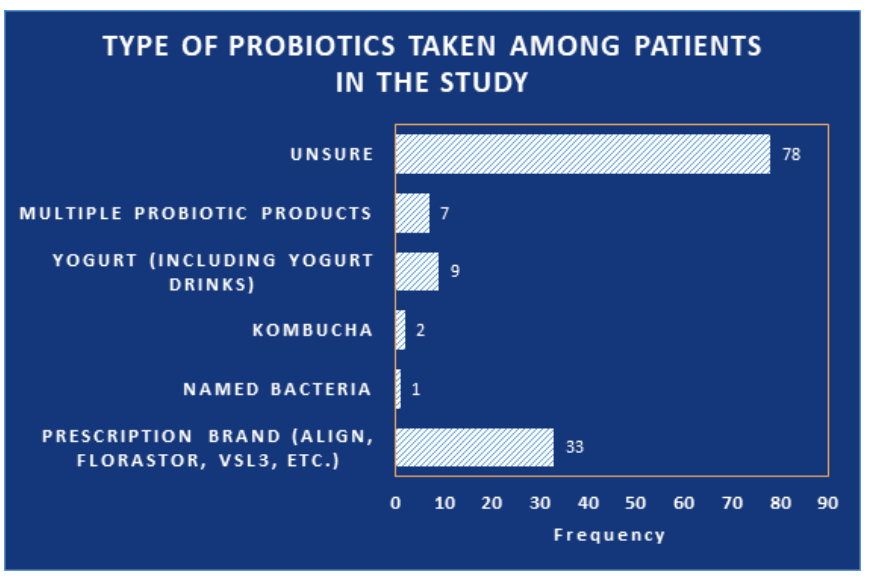

Figure 2 Types of probiotics taken among 479 general gastroenterology patients.

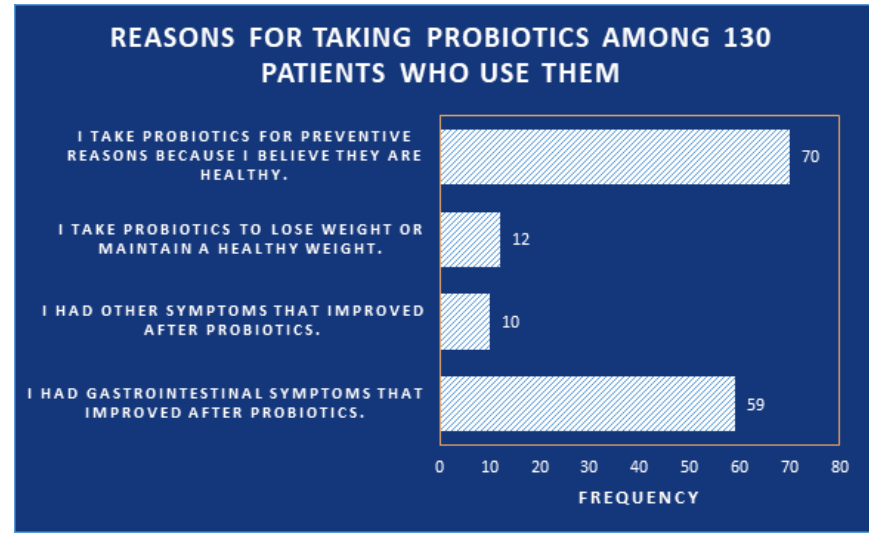

Figure 3 Reasons for using probiotics, among patients who use them. Patients could list multiple reasons.

be scheduled for a procedure because of symptoms (as opposed to preventive health), and to report specific gastrointestinal symptoms (table 2). The most common specific symptoms reported among probiotic users were bloating ( $40 \%, \mathrm{p}<0.01$ vs non-users), heartburn (34\%, $\mathrm{p}=0.06)$ and abdominal pain $(23 \%, \mathrm{p}=0.04)$. To evaluate the independent association of specific gastrointestinal symptoms and probiotic use, we built a multivariable model incorporating all specific symptoms. In the multivariable analysis, only bloating was independently associated with use of probiotics (adjusted OR 2.59, 95\% CI 1.52 to 4.44 , (online supplemental table 2).

\section{Views about probiotics, comparing those who do versus those who do not use them}

Last, using a series of Likert scale questions, we elicited views about probiotics among patients who do and do not use them. Compared with non-users, users of probiotics rated probiotics as more important for gastrointestinal symptoms, health and longevity, overall symptoms and maintenance of a healthy weight $(p<0.01$ for all comparisons, figure 4). Of these categories, the difference between users and non-users was most striking for gastrointestinal symptoms. Finally, study participants were asked about the gut microbiome. Compared with non-users, probiotic users were more likely to rate the gut microbiome as important for gastrointestinal health and to rate themselves as knowledgeable about the gut microbiome ( $\mathrm{p}<0.01$ for both comparisons).

\section{DISCUSSION}

This was an endoscopy suite-based survey study of general gastroenterology patients with a $90 \%$ response rate. We found that almost one third of patients had used probiotics recently. Bloating was more closely associated with use of probiotics than diarrhoea. To our surprise, probiotics users had similar demographics compared with non-users (age, sex, race/ethnicity and income). Rather, the most marked differences between probiotics users and non-users were related to beliefs. Users of probiotics reported beliefs that probiotics benefit overall health, 


\begin{tabular}{|c|c|c|c|}
\hline Characteristics & $\begin{array}{l}\text { Probiotics } \\
\mathrm{N}=130 \\
(27 \%) \\
\end{array}$ & $\begin{array}{l}\text { No probiotics } \\
\mathrm{N}=349 \\
(73 \%)\end{array}$ & $P$ value \\
\hline Age (years) & & & 0.25 \\
\hline $20-50$ & $52(31 \%)$ & $115(69 \%)$ & \\
\hline $51-65$ & $48(27 \%)$ & $127(73 \%)$ & \\
\hline$\geq 66$ & $28(29 \%)$ & $97(77 \%)$ & \\
\hline Language & & & 0.64 \\
\hline English & $124(27 \%)$ & $329(73 \%)$ & \\
\hline Spanish only & $6(23 \%)$ & $20(77 \%)$ & \\
\hline Race & & & 0.60 \\
\hline White & $80(26 \%)$ & $223(74 \%)$ & \\
\hline Hispanic & $24(24 \%)$ & $76(76 \%)$ & \\
\hline Black & $11(29 \%)$ & $27(71 \%)$ & \\
\hline Other & $13(40 \%)$ & $19(59 \%)$ & \\
\hline Ethnicity & & & 0.60 \\
\hline Non-Hispanic & $69(28 \%)$ & $176(72 \%)$ & \\
\hline Hispanic & $26(23 \%)$ & $85(77 \%)$ & \\
\hline Other & $32(29 \%)$ & $80(71 \%)$ & \\
\hline Married & $75(26 \%)$ & $213(74 \%)$ & 0.53 \\
\hline Children & & & 0.13 \\
\hline No children & $45(32 \%)$ & $95(68 \%)$ & \\
\hline 1-2 children & $58(27 \%)$ & $153(73 \%)$ & \\
\hline$\geq 3$ children & $27(21 \%)$ & $101(79 \%)$ & \\
\hline Household members & & & 0.76 \\
\hline 1 other person & $29(30 \%)$ & $68(70 \%)$ & \\
\hline 2-3 other people & $71(26 \%)$ & $202(74 \%)$ & \\
\hline$\geq 4$ other people & $30(27 \%)$ & $79(73 \%)$ & \\
\hline Dog owner & $41(33 \%)$ & $83(67 \%)$ & 0.08 \\
\hline Cat owner & $18(30 \%)$ & $43(70 \%)$ & 0.62 \\
\hline Educational level & & & 0.73 \\
\hline College graduate & $81(27 \%)$ & $224(73 \%)$ & \\
\hline $\begin{array}{l}\text { Not college } \\
\text { graduate }\end{array}$ & $46(28 \%)$ & 118 (72\%) & \\
\hline Insurance status & & & 0.34 \\
\hline Medicare/Medicaid & $36(24 \%)$ & $113(76 \%)$ & \\
\hline $\begin{array}{l}\text { Commercial } \\
\text { insurance }\end{array}$ & $89(28 \%)$ & $225(72 \%)$ & \\
\hline Income* & & & 0.78 \\
\hline US\$21 542-56863 & $43(28 \%)$ & $109(72 \%)$ & \\
\hline US\$58 331-97286 & $43(29 \%)$ & $104(71 \%)$ & \\
\hline > US\$97920 & $38(26 \%)$ & $110(74 \%)$ & \\
\hline
\end{tabular}

*Estimated based on median income from zip code of residence.

Column totals are unequal due to rare missing data.

t $\chi^{2}$ test.

gastrointestinal health, longevity, maintenance of a healthy weight and benefits for the microbiome.

Medical professionals are a trusted source of information and understanding the patient's knowledge base is crucial for an effective patient-physician relationship. ${ }^{12}$
Table 2 Symptoms of those who do and do not use probiotics

\begin{tabular}{|c|c|c|c|}
\hline Characteristics & $\begin{array}{l}\text { Probiotics } \\
\mathrm{N}=130(27 \%)\end{array}$ & $\begin{array}{l}\text { No probiotics } \\
N=359 \\
(73 \%)\end{array}$ & $\mathbf{P}$ value \\
\hline $\begin{array}{l}\text { Reasons for } \\
\text { procedure }\end{array}$ & & & 0.05 \\
\hline Routine screening* & $60(25 \%)$ & $182(75 \%)$ & \\
\hline Symptoms & $31(39 \%)$ & $49(61 \%)$ & \\
\hline Unsure & $4(16 \%)$ & $21(84 \%)$ & \\
\hline Other & $35(27 \%)$ & $97(73 \%)$ & \\
\hline Symptoms & & & 0.03 \\
\hline No symptoms & $41(21 \%)$ & $149(78 \%)$ & \\
\hline Some symptoms & $89(31 \%)$ & $200(69 \%)$ & \\
\hline \multicolumn{4}{|c|}{ Specific gastrointestinal symptoms } \\
\hline Bloating & $52(43 \%)$ & $70(57 \%)$ & $<0.01$ \\
\hline Constipation & $25(38 \%)$ & $41(62 \%)$ & 0.03 \\
\hline Pain & $30(36 \%)$ & $54(64 \%)$ & 0.04 \\
\hline Diarrhoea & $22(35 \%)$ & $40(65 \%)$ & 0.10 \\
\hline $\begin{array}{l}\text { Swallowing } \\
\text { problems }\end{array}$ & $7(35 \%)$ & $13(65 \%)$ & 0.40 \\
\hline Heartburn & $44(33 \%)$ & $90(67 \%)$ & 0.06 \\
\hline Incontinence & $7(32 \%)$ & $15(68 \%)$ & 0.58 \\
\hline
\end{tabular}

*Including screening/surveillance procedures for colon cancer or polyps and for Barrett's oesophagus.

$+\chi^{2}$ test.

The results of this study make it clear that a significant portion of the gastroenterology patient population uses probiotics to some degree, and that the most common reason for doing so is belief in general health benefits as opposed to belief in specific gastrointestinal health benefits. Interestingly, patients were equally likely to use probiotics for diarrhoea as they were for constipation. An understanding of patient expectations will allow practitioners to better prepare for comprehensive discussions

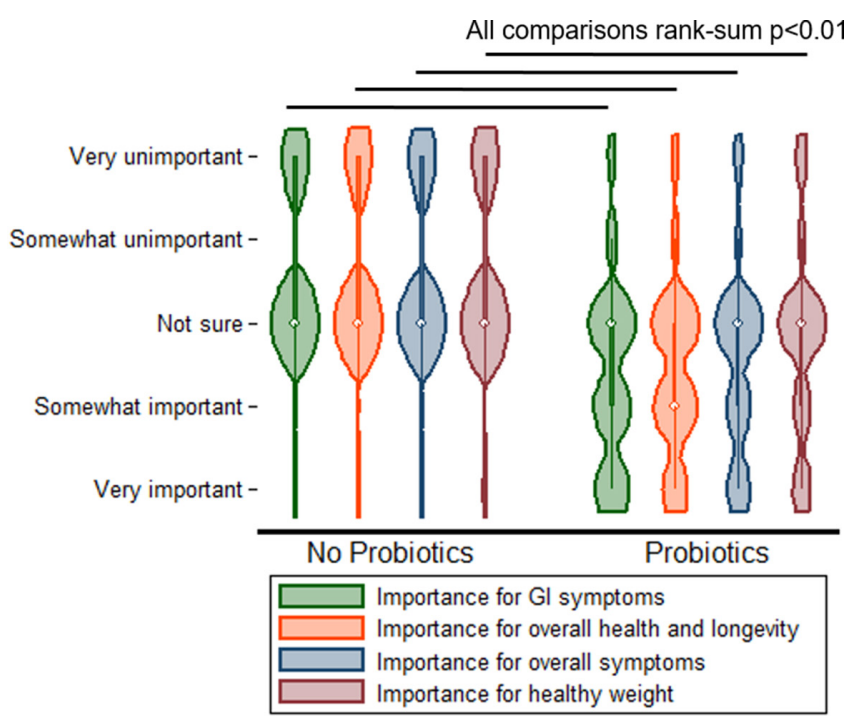

Figure 4 Views on the benefits of probiotics, comparing probiotics users and non-users. 
about the therapeutic use of probiotics. Clinicians can use this knowledge to hone their questions when discussing probiotics or alternative and complementary therapies with their patients.

As use of probiotics has become more common, the literature regarding effect has become more robust. Most prior studies of probiotics studies test the effectiveness of certain probiotic strains in treating various gastrointestinal conditions. Results of these studies are conflicting, likely due to the varying stool collection methodology, clinical endpoints and the large number of individually studied probiotic strains which are often formulated in combinations. ${ }^{1314}$ A 2021 guideline from the AGA found evidence supporting the health benefits of probiotics in four specific instances: prevention of Clostridioides difficile infection among those taking antibiotics, pouchitis, acute gastroenteritis in children and for preterm infants. ${ }^{3}$ Even in these targeted situations, the AGA's recommendations for probiotics were conditional and based on relatively few rigorous studies. Meanwhile, the preclinical literature related to probiotics suggests the possibility of benefit for conditions ranging from colon cancer ${ }^{15}$ to diabetes ${ }^{16}$ and is expanding rapidly. In this survey, users of probiotics indicated that they were more likely to take probiotics for general reasons (longevity, health/well-being) rather than for specific diseases or symptoms. Probiotics users may be excited by the potential of probiotics, perceive few downsides, and less attuned to evidence than medical professionals.

Only a few prior studies have sought to identify the prevalence of probiotic use. ${ }^{71718}$ Dimidi et al conducted an online study to discern the prevalence and selfreported effectiveness of probiotics use among the general public in the UK. ${ }^{7}$ This study sought to exclude individuals with gastrointestinal diseases. However, of the final 2557 participants, over half self-reported constipation and $37 \%$ of these respondents had tried probiotics (vs $11 \%$ of those without constipation). ${ }^{7}$ The study did not question participants directly about specific gastrointestinal symptoms other than constipation and, because it was internet-based, the response rate was unknown. Additionally, the study found that among those who reported experiencing constipation, factors associated with probiotic use were having visited a complementary and alternative therapist for their constipation symptoms and believing that probiotics have been tested in research studies. ${ }^{7}$ While our study did not ask any questions about alternative therapies, the Dimidi et al study suggests that using general alternative therapies may be a strong indicator for probiotic use.

Other studies have examined probiotics under the broader umbrella of complementary and alternative medicines (CAM). A study out of the University of Florida used an online survey of the general population to gather information on CAM use both for general health purposes as well as specific gastrointestinal symptom relief. ${ }^{19}$ Respondents self-reported the severity of varying gastrointestinal symptoms. The three most common symptoms (rated on a scale of severity) were early satiety, nausea and bloating. ${ }^{19}$ Regarding treatment of selfreported symptoms, respondents preferred to use probiotics for bloating, upset stomach and indigestion. ${ }^{19}$ Of those who found CAMs effective in managing gastrointestinal symptoms, $31 \%$ of them took probiotics. Somewhat suprisingly, those who used probiotics rated individual gastrointestinal symptoms as mostly unchanged by probiotic use ${ }^{19}$ Like this study, our findings are consistent with the conclusion that patients reach for probiotics for a diverse set of gastrointestinal and non-gastrointestinal symptoms, motivated by beliefs in overall health benefits.

Probiotics have been defined by the FAO/WHO as live microorganisms which confer health benefits when ingested, ${ }^{1}$ but the lone term 'probiotic' does not well distinguish between the varied biology of the products identified by survey respondents in this study as probiotics (which ranged from kambucha to named organisms). Some have advocated that more precise terminology ${ }^{20}$ would better capture the mechanisms of differing probiotics $^{21}$ and it seems likely that additional survey respondents do not perceive themselves as users of probiotics yet ingest products such as fermented milk which may exert microbiome-based health effects. ${ }^{22}{ }^{23}$ These study results show that many individuals are taking varied products that are all perceived to be probiotics, often hoping for generalised health benefits.

The study has strengths. The survey response rate was high $(90 \%)$ and therefore our prevalence of use estimate of $27 \%$ can reasonably be assumed to approximate the prevalence of use of probiotics use in most general gastroenterology populations. Additionally, the socioeconomic demographics of the survey respondents are broadly representative of the US population. An important limitation is that the study was conducted in the endoscopy suite of a single academic medical centre and included patients who were having endoscopies that were performed both for screening and for diagnostic purposes (ie, there were survey respondents with and without symptoms). Reassuringly, the rates of probiotic use differed little between those having screening versus diagnostic procedures. While we believe that these results can reasonably be generalised to most gastroenterology patients, they should not be generalised to other patient populations (eg, general medicine patients).

In sum, probiotics users were similar to non-users in sociodemographics but differed in gastrointestinal symptoms and in how they perceived probiotics: users believed that probiotics had broad beneficial properties whereas non-users were more sceptical. Bloating, not diarrhoea, was the gastrointestinal symptom most strongly associated with use of probiotics. Clinicians must recognise and address patients' beliefs regarding probiotics to be effective advisors to patients.

Contributors EL and JT gathered data and performed initial analyses; EL wrote the manuscript first draft. BL assisted in study design, analyses and manuscript revision. DEF conceived and planned the study, performed the final analyses and 
critically revised the manuscript. All authors have seen and approved the final manuscript.

Funding DEF was supported in part by a Department of Defense Peer Reviewed Medical Research Program Clinical Trial Award (PR181960) and by the Columbia University Irving Medical Center Irving Scholar Award.

Competing interests None declared.

Patient consent for publication Not required.

Ethics approval This study was approved by the institutional review board of CUIMC.

Provenance and peer review Not commissioned; externally peer reviewed.

Data availability statement All data relevant to the study are included in the article or uploaded as supplementary information. Raw data variables correspond to the items on the questionnaire.

Supplemental material This content has been supplied by the author(s). It has not been vetted by BMJ Publishing Group Limited (BMJ) and may not have been peer-reviewed. Any opinions or recommendations discussed are solely those of the author(s) and are not endorsed by BMJ. BMJ disclaims all liability and responsibility arising from any reliance placed on the content. Where the content includes any translated material, BMJ does not warrant the accuracy and reliability of the translations (including but not limited to local regulations, clinical guidelines, terminology, drug names and drug dosages), and is not responsible for any error and/or omissions arising from translation and adaptation or otherwise.

Open access This is an open access article distributed in accordance with the Creative Commons Attribution Non Commercial (CC BY-NC 4.0) license, which permits others to distribute, remix, adapt, build upon this work non-commercially, and license their derivative works on different terms, provided the original work is properly cited, appropriate credit is given, any changes made indicated, and the use is non-commercial. See: http://creativecommons.org/licenses/by-nc/4.0/.

ORCID iD

Daniel E Freedberg http://orcid.org/0000-0003-2023-2899

\section{REFERENCES}

1 WHO. Report on evaluation of health and nutritional properties of probiotics in food including powder milk with live lactic acid bacteria. Available: http://pcilelehk/public/pdf/20190225/ bd3689dfc2fd663bb36def1b672ce0a4pdf [Accessed 2 Aug 2021].

2 Vasant DH, Paine PA, Black CJ, et al. British Society of gastroenterology guidelines on the management of irritable bowel syndrome. Gut 2021;70:1214-40.

3 Su GL, Ko CW, Bercik P, et al. AGA clinical practice guidelines on the role of probiotics in the management of gastrointestinal disorders. Gastroenterology 2020;159:697-705.

4 Wire TE. Probiotics market 2019 global industry trends, share, size, demand, growth opportunities, industry revenue, future and business analysis by forecast - 2025. The Express Wire, 2019. Available: https://www.theexpresswire.com/pressrelease/Probiotics-
Market-2019-Global-Industry-Growth-Analysis-Segmentation-SizeShare-Trend-Future-Demand-and-Leading-Players-Updates-byForecast-to-2025_10399806

5 Jackson C. Trends in the use of complementary health approaches among adults in the United States: new data. Holist Nurs Pract 2015;29:178-9.

6 Health Nlo. probiotics: what you need to know, 2019. Available: https://nccih.nih.gov/health/probiotics/introduction.htm

7 Dimidi E, Cox C, Scott SM, et al. Probiotic use is common in constipation, but only a minority of general and specialist doctors recommend them and consider there to be an evidence base. Nutrition 2019;61:157-63.

8 Thompson FE, Midthune D, Subar AF, et al. Performance of a short tool to assess dietary intakes of fruits and vegetables, percentage energy from fat and fibre. Public Health Nutr 2004;7:1097-106.

9 Thompson FE, Midthune D, Subar AF, et al. Dietary intake estimates in the National health interview survey, 2000: methodology, results, and interpretation. J Am Diet Assoc 2005;105:352-63.

10 Bureau USC. American fact finder, 2020. Available: https://factfinder. census.gov/faces/tableservices/jsf/pages/productview.xhtml?pid= ACS_17_5YR_S1901\&prodType=table

11 Bureau USC. Quick facts United States, 2019. Available: https:// www.census.gov/quickfacts/fact/table/US

12 Honavar SG. Patient-physician relationship - Communication is the key. Indian J Ophthalmol 2018;66:1527-8.

13 Suez J, Zmora N, Segal E, et al. The pros, cons, and many unknowns of probiotics. Nat Med 2019;25:716-29.

14 Sharp RR, Achkar J-P, Brinich MA, et al. Helping patients make informed choices about probiotics: a need for research. Am J Gastroenterol 2009;104:809-13.

15 Balthazar CF, de Moura NA, Romualdo GR, et al. Synbiotic sheep milk ice cream reduces chemically induced mouse colon carcinogenesis. J Dairy Sci 2021;104:7406-14.

16 Grom LC, Rocha RS, Balthazar CF, et al. Postprandial glycemia in healthy subjects: which probiotic dairy food is more adequate? $J$ Dairy Sci 2020;103:1110-9.

17 Land $\mathrm{MH}$, Wang J. Complementary and alternative medicine use among allergy practices: results of a nationwide survey of allergists. J Allergy Clin Immunol Pract 2018;6:95-8.

18 Ciernikova S, Mego M, Semanova M, et al. Probiotic survey in cancer patients treated in the outpatient department in a comprehensive cancer center. Integr Cancer Ther 2017;16:188-95.

19 Grundmann O, Yoon SL, Mason S, et al. Gastrointestinal symptom improvement from fiber, STW 5, peppermint oil, and probiotics use-Results from an online survey. Complement Ther Med 2018;41:225-30.

20 Zendeboodi F, Khorshidian N, Mortazavian AM, et al. Probiotic: conceptualization from a new approach. Curr Opin Food Sci 2020;32:103-23.

21 Chugh B, Kamal-Eldin A. Bioactive compounds produced by probiotics in food products. Curr Opin Food Sci 2020;32:76-82.

22 Lee CS, Lee SH, Kim SH. Bone-protective effects of Lactobacillus plantarum B719-fermented milk product. Int J Dairy Technol 2020;73:706-17.

23 Eor JY, Tan PL, Son YJ, et al. Milk products fermented by Lactobacillus strains modulate the gut-bone axis in an ovariectomised murine model. Int J Dairy Technol 2020;73:743-56. 